\title{
FACHADAS ATIVAS E SUA INFLUÊNCIA NA QUALIDADE DE VIDA URBANA
}

\author{
Bárbara Klóss Teixeira ${ }^{1}$ \\ André de Souza Silva²
}

DOI: 10.5752/P.2316-1752.2017v25n36p206

\section{Resumo}

O objetivo deste artigo é determinar diretrizes que promovam o uso de fachadas ativas, analisando os aspectos que proporcionam maior variedade de experiências percebidas pelas pessoas em movimento pelo espaço aberto público em busca de orientar a elaboração de projetos urbanísticos e arquitetônicos. Os procedimentos metodológicos estão centrados na abordagem da cidade sob o ponto de vista da escala humana e no estudo de caso, realizado no bairro Moinhos de Vento - Porto Alegre, que, em razão de sua diversidade socioespacial, contribuiu para a análise interpretativa dos resultados. As principais diretrizes estabelecidas consistem em: (i) diversidade de usos; (ii) centralidade; (iii) acessos; (iv) permeabilidade nas fachadas; (v) altura das edificações; (vi) regularidade no alinhamento; (vii) identida-

1. Mestre em Arquitetura e Urbanismo. Universidade do Vale do Rio dos Sinos. e-mail: barbara.bkt@gmail.com

2. Doutor em Planejamento Urbano e Regional. Universidade do Vale do Rio dos Sinos.

E-mail: silandre@unisinos.br 
de; (viii) zona de proteção; (ix) extensão das quadras; e (x) transformação dos espaços. Dessa forma, é possível incentivar a aplicação de fachadas ativas no espaço urbano de modo a contribuir com a qualidade de vida do ambiente.

Palavras-chave: Fachadas ativas. Urbano. Movimento de pedestre. Planejamento. Diretrizes. 


\section{ACTIVE FAÇADES AND THEIR INFLUENCE ON URBAN QUALITY OF LIFE}

\begin{abstract}
The objective of this article is to determine directives that promote the use of active façades, analyzing the aspects that provide greater variety of experiences perceived by people moving through public open space, in an attempt to give guidance to the development of urban and architecture projects. The methodological procedures are centered on the approach of the city under the viewpoint of human scale, and on the case study, conducted in the District of Moinhos de Vento - Porto Alegre, which, by virtue of its socio-spatial diversity, contributed toward the interpretative analysis of the results. The main guidelines established consist of: (i) diversity of uses; (ii) centrality; (iii) accesses; (iv) facade permeability; (v) height of buildings; (vi) regularity in alignment; (vii) identity; (viii) protection zone; (ix) extension of the blocks; and, $(x)$ transformation of spaces. Thus it is possible to encourage the application of active façades in the urban space to contribute to the quality of life of the environment.
\end{abstract}

Keywords: Active facades. Urban. Pedestrian movement. Planning. Guidelines.
FACHADAS ATIVAS Y SU INFLUENCIA EN LA CALIDAD DE VIDA URBANA

\section{Resumen}

El objetivo de la investigación es determinar directrices que promuevan el uso de fachadas activas, analizando los aspectos que proporcionan mayor variedad de experiencias percibidas por las personas en movimiento por el espacio abierto público, buscando orientar la elaboración de proyectos urbanísticos y arquitectónicos. Los procedimientos metodológicos se centran en el enfoque de la ciudad desde el punto de vista de la escala humana, y en el estudio de caso, realizado en el Barrio Moinhos de Vento - Porto Alegre, que, en razón de su diversidad socioespacial, contribuyó al análisis interpretativo de los resultados. Las principales directrices establecidas consisten en: (i) diversidad de usos; (ii) centralidad; (iii) accesos; (iv) permeabilidad en las fachadas; (v) altura de las edificaciones; (vi) regularidad en la alineación; (vii) identidad; (viii) zona de protección; (ix) extensión de las cuadras; y (x) transformación de los espacios. Así es posible incentivar la aplicación de fachadas activas en el espacio urbano para contribuir con la calidad de vida del ambiente.

Palabras-claves: Fachadas activas. Urbano. Movimiento de peatones. Planificación. Directrices. 


\section{Introdução}

A presença de térreos permeáveis contribui para que o espaço urbano, por meio do incentivo à movimentação de pedestres, se torne mais animado, atraente e ativo. A partir do momento em que as pessoas se apropriam do espaço urbano, ocupando os espaços públicos como parques, praças e calçadas, ocorre o aumento da segurança por meio da vigilância natural, beneficiando tanto os visitantes quanto os moradores do lugar.

Fachadas ativas são definidas por edificações e suas respectivas atividades localizadas no limite do alinhamento das calçadas, cuja relação do espaço privado com o espaço aberto público ocorre de modo direto a partir de aberturas com acesso livre (SÃO PAULO, 2014), trazendo movimento ao seu entorno (figura 1). Essa estratégia de interface e transição promove a interação de pessoas e fortalece a vida cotidiana, no sentido da reconquista da rua como lugar de convívio social. As fachadas ativas estão integradas ao passeio e subsidiadas pela zona de proteção, que faz a interface entre o movimento de pedestres e veículos.

Aguiar e Netto (2012) afirmam que a presença de aberturas, a partir do térreo, diminui os índices de criminalidade, sugerindo segurança e acolhimento. Em contrapartida, fachadas formadas por muros altos tornam o ambiente inós- 
pito, afastando os pedestres das calçadas. Térreos privados e cercados por muros e guarita rompem a continuidade com o espaço externo, diminuindo a segurança das ruas no entorno a partir da redução das relações geradoras de movimento. Cullen (2015) defende a ideia de que qualquer intervenção urbana é percebida pelo observador, incluindo os muros, presentes na paisagem urbana, de modo que nunca devem ser vazios ou monótonos.

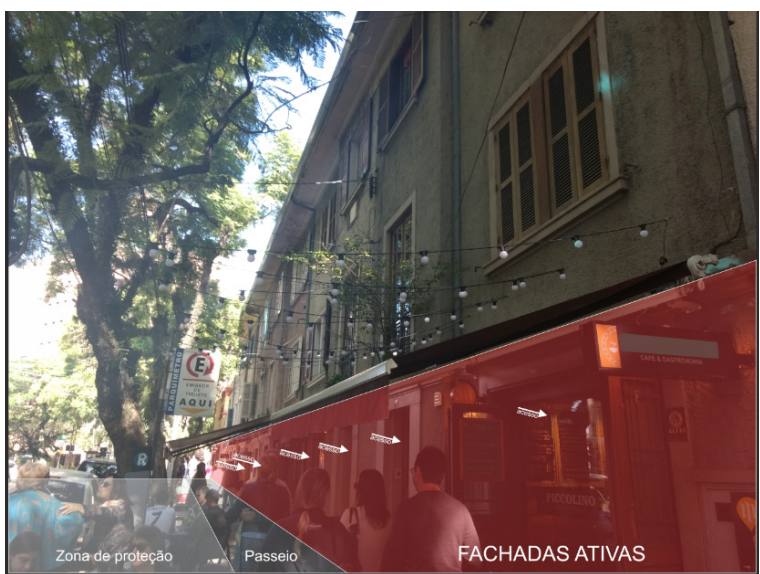

Figura 1 | Relação entre fachadas ativas, espaço aberto público e pessoas na Rua Feliz da Cunha. Fonte: Acervo dos Autores (2018)

A interação de pedestres e atividades é realizada, fundamentalmente, por meio da permeabilidade, que pode ser física ou visual (VIVIAN, 2012). Ela ocorre quando as aberturas se conectam à rua, permitindo que o pedestre explore 
e reconheça alguns aspectos do ambiente interno. Já na situação oposta, uma rua com alta proporção de muros e fachadas sem aberturas gera o sentimento de perigo, fragilidade e desconfiança, na medida em que referências visuais não são encontradas. De fato, a permeabilidade transcorre no momento em que existe algum tipo de acesso físico entre o espaço edificado e o aberto. Nesse sentido, alguém que está dentro de uma edificação, com contato direto para o espaço público, sente-se identificado, possibilitando a integração passiva (quando o contato do pedestre com o interior das edificações incide de maneira visual, olfativa ou auditiva) ou ativa (quando o pedestre acessa fisicamente $\mathrm{o}$ interior do térreo das edificações).

As fachadas ativas evitam a formação de planos fechados na interface entre os espaços públicos e privados, promovendo a dinamização das calçadas. Por outro lado, planos fechados desfavorecem o convívio entre pessoas de classes sociais diferentes e o bem-estar dos pedestres, na medida em que caminham por calçadas envolvidas por muros altos, sem atrativos e inseguras devido à ausência de pessoas.

Diante do exposto, a questão que se coloca é: quais características presentes nas fachadas ativas são capazes de subsidiar diretrizes para o planejamento de áreas da cidade, influenciando a qualidade de vida urbana? Considera-se 
interessante que a permeabilidade incida nas fachadas de modo a integrar tanto pedestres quanto moradores, a fim de realizar a transição eficiente do espaço público para o privado. Essa permeabilidade é influenciada pela estrutura, tipos de revestimento, volumetria das edificações, dimensões do passeio, mobiliário urbano, incidência de iluminação e pelo movimento de pedestres e veículos.

O objetivo da pesquisa é observar os principais elementos presentes em fachadas ativas, a fim de compor diretrizes alternativas capazes de promover a ambiência urbana. Em específico, para determinar diretrizes alternativas de planejamento urbano que tornam a relação entre espaço público 212 e edificações interessante, foi realizado um estudo de caso no bairro Moinhos de Vento - Porto Alegre com o propósito de entender os elementos principais, presentes nas fachadas ativas, que influenciam a qualidade de vida urbana, no qual foi analisado o comportamento dos pedestres frente às fachadas permeáveis e a relação dos elementos presentes nas fachadas e nos passeios que influenciam significativamente a vida urbana.

A discussão sobre fachadas ativas é relevante por atrair as pessoas aos espaços abertos, pois, atualmente, existe uma tendência de permanência das pessoas em ambientes fechados. A integração entre os espaços públicos e privados, por meio das fachadas ativas, contribui com o sentimento 
de pertencimento do local, por parte dos moradores, agregando valor aos aspectos culturais presentes no espaço. Cabe salientar que as estratégias projetuais relacionadas às fachadas ativas visam auxiliar os gestores e projetistas, contribuindo com o desenvolvimento da economia, do convívio social entre os moradores e, principalmente, da qualidade de vida nas cidades.

Como método, o levantamento da literatura expôs conceitos relacionados às fachadas ativas, abordando os aspectos inerentes à qualidade ambiental da paisagem urbana (KARSSENBERG et al, 2015; GEHL, 2013; HERTZBERGER, 1999). De modo a compreender a influência das fachadas ativas na ambiência do espaço, elaborou-se um estudo de caso no bairro Moinhos de Vento, localizado na cidade de Porto Alegre, estruturado por pesquisas no acervo histórico da cidade, análise de fotografias e interpretação de mapas esquemáticos, de modo a embasar a proposição de diretrizes para implantação de fachadas ativas.

\section{Fundamentação: fachadas ativas como conceito}

Configurações espaciais caracterizadas por edificações verticalizadas impactam na paisagem urbana e exercem efeitos psicológicos negativos nos pedestres que convivem com essa monumentalidade todos os dias. Karssenberg 
et al (2015) abordam o conceito de "zona híbrida", que corresponde à zona de transição entre o espaço público e o privado (figura 2). Segundo os autores, esse ambiente é de extrema importância, pois ali se formam as relações entre as pessoas que usufruem do espaço público e as pessoas que utilizam o interior das edificações.

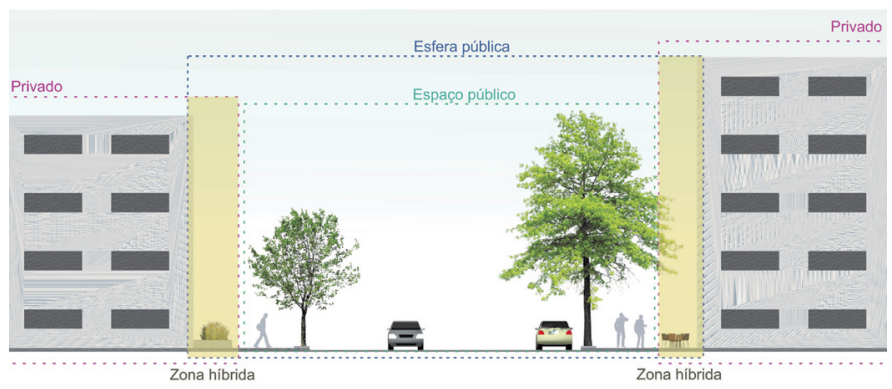

Figura 2 | Esquema da esfera pública e o espaço privado. Fonte: Adaptado de Karssenberg et al (2015).

Essa integração acontece por meio de atrativos existentes nas zonas híbridas, que chamam atenção dos pedestres e, ao mesmo tempo, permitem que os proprietários personalizem o espaço lindeiro às edificações, criando identidade $e$ auxiliando no senso de orientabilidade. A zona híbrida pode ser formada por diversos elementos que realizam a integração do pedestre com o espaço privado, seja ele comercial ou residencial. Esses elementos podem consistir em bancos e mesas, vegetação, fachadas permeáveis, calçamento 
diferenciado, alternância nos níveis do passeio, entre outros.

Hertzberger (1999) também comenta a respeito da transição entre o público e o privado no ambiente urbano, chamando esse fenômeno de "intervalo". O autor ressalta a importância dos elementos intermediários nas zonas de "intervalo", dando como exemplos: (i) degraus; (ii) vitrines; (iii) portas; e (iv) janelas, visto que, quando acessados por ambos os públicos (pedestres e moradores), esses elementos fazem com que os limites dos lotes e dos passeios se tornem mais tênues e integrados.

As fachadas ativas são efetivas na atuação da harmonização nos espaços híbridos. A relação entre o público em geral com o interior das edificações faz com que melhore a segurança do espaço devido à maior movimentação de pessoas no lugar. A segurança, por sua vez, atrai mais pessoas, que se sentem confortáveis ao transitar por esses espaços. Esse aumento da movimentação de pessoas também promove o desenvolvimento dos estabelecimentos localizados no térreo. Portanto, o emprego de fachadas ativas, no contexto urbano, gera um ciclo de benefícios aos diversos tipos de público.

É no andar térreo que as pessoas têm o contato imediato com as edificações. Moradores e visitantes transitam nos 
acessos, ocupando a zona híbrida. Conforme afirma Karssenberg et al (2015), quando cadeiras e mesas estão dispostas ao longo das fachadas, os acessos às edificações acabam sendo facilitados e também ocorre a proteção daqueles que estão sentados. Ainda segundo Karssenberg et al (2015), fachadas do andar térreo são lugares atraentes também para pessoas que não vivem nas edificações, fazendo com que as zonas de transição entre as edificações e os ambientes urbanos se tornem o espaço natural para atividades diversas que conectam as funções interiores com a vida urbana. Cullen (2015) também aponta para a importância do pavimento como o conceito de um elemento ativo, visto que possui o seu próprio "carácter e personalidade", sendo um dos componentes essenciais responsáveis pela unificação da cidade.

É possível configurar as calçadas de modo que fiquem mais seguras e atrativas para as pessoas por meio da inserção de diretrizes que fortaleçam o emprego de fachadas ativas no meio urbano. Mudanças na composição do desenho e da estrutura do piso térreo em edificações podem interferir na forma como a cidade é percebida. Cidades como Amsterdã (AMSTERDAM, 2016), Estocolmo (STOCKHOLMS, 2018), Melbourne (MELBOURNE, 2018), São Paulo (SÃO PAULO, 2014), Curitiba (CURITIBA, 2015) e Belo Horizonte (BELO HORIZONTE, 2017) estabeleceram diretrizes para a implementação desse conceito, determinando, em legisla- 
ção específica, o número mínimo de entradas que devem existir em uma edificação, conforme o comprimento do passeio e os critérios para a relação de permeabilidade visual entre as edificações e o espaço aberto público.

Nesses casos, o ambiente urbano se relaciona diretamente com a maneira pela qual as cidades são desenhadas e construídas. Espaços de qualidade consideram a necessidade natural das pessoas pela diversidade de estímulos sensoriais, originando ambientes confortáveis que promovem a convivência e o bem-estar das pessoas.

Em sua pesquisa, a respeito da reação das pessoas no espaço urbano, Jan Gehl (2013) percebeu que pedestres caminham com o passo mais apressado ao passarem diante de fachadas inativas, mas, em contrapartida, caminham mais devagar ao transitarem em espaços com fachadas permeáveis. Gehl estabeleceu que uma rua de qualidade necessita ser projetada de modo que as pessoas, que se locomovem a $5 \mathrm{~km} / \mathrm{h}$ em média, observem algo que thes chame a atenção ao menos uma vez a cada cinco segundos, o que não acontece em frente a fachadas cegas (PACHECO, 2016).

Segundo Karssenberg et al (2015), pedestres precisam estar localizados em um ponto mais distante para que consigam visualizar uma edificação no seu conjunto. Quando a 
pessoa se aproxima ainda mais da edificação, os pavimentos mais altos ficam imperceptíveis gradualmente, até que apenas o térreo seja percebível no campo de visão, sendo que, a partir desse ponto, os detalhes nas fachadas se mostram compreensíveis e os sentidos são estimulados. As fachadas térreas interferem intensamente na percepção das pessoas, de modo que, quanto maior a distância, menor a intensidade dos estímulos recebidos. A percepção é influenciada não só pelo ponto de vista como também pela rapidez do movimento.

A apropriação da zona híbrida cria, ainda, um sentido de alteridade que, se bem empregado, pode resultar em uma leitura da identidade do conjunto do entorno. Estabelecimentos pequenos, familiares e especializados criam um caráter único, aspecto importante para a qualidade perceptiva do espaço. A orientabilidade também se faz presente nos espaços, a partir do momento em que se estabelece uma personalidade diferenciada do restante da cidade. A orientação do pedestre é de extrema importância para que ele inclua esse ambiente em seu percurso. Pessoas costumam se sentir mais seguras e confortáveis em locais que já possuem algum tipo de referência e que possibilitem se localizar no espaço com facilidade.

Jacobs (1993) afirma que a ligação visual entre o interior e o exterior de edificações é importante para conectar os espa- 
ços público e privado. O contato visual pelos pedestres nas calçadas aumenta as oportunidades oferecidas, sendo um aspecto importante para que o pedestre tenha uma experiência satisfatória. Deve-se observar o número de portas, janelas, recuos, vitrines, letreiros e decorações.

O projeto das ruas deve incentivar o livre acesso e interação das pessoas. Para isso, é interessante priorizar pedestres e desacelerar o tráfego de veículos na cidade, sem eliminar o trânsito motorizado, pois, em certos momentos, espaços precisam permitir um movimento maior, enquanto que, em outros casos, eles necessitam de períodos de tranquilidade. O movimento de pessoas pode variar ao longo do dia ou do período anual. Usos diversificados no espaço público podem ser incitados por meio da implantação de alguns elementos, por exemplo: escadarias, bordas altas nos canteiros, dentre outros.

Há lugares movimentados e lugares que são menos frequentados, porém funcionam perfeitamente na esfera pública. O ambiente urbano incorpora as características dos diversos grupos da cidade, permitindo momentos de intensidade nos seus espaços comerciais animados e momentos de folga nos seus quarteirões residenciais, por meio da definição de uma hierarquia. É indispensável analisar os setores em áreas urbanas onde possa se estabelecer ambientes de convívio. Segundo Karssenberg et al (2015), 
deve-se considerar as rotas de pedestres mais significativas, sendo que um projeto deve atribuir qualidade para os espaços públicos mais relevantes da cidade.

Segundo Gehl (2013), a velocidade dos passos do pedestre pode ser influenciada por fatores como: qualidade do percurso, conservação do pavimento, quantidade de pessoas e idade do pedestre. O autor diz ainda que os pedestres andam mais rápido em ruas que convidam ao movimento linear, ao passo que o ritmo cai quando atravessam praças e parques. O clima também influencia na velocidade do caminhar dos pedestres; em ambientes chuvosos, frios ou com ventos, a velocidade das pessoas tende a diminuir. Vale ressaltar, além disso, que as pessoas tendem a caminhar mais rápido em ruas extensas e monótonas.

O senso de localização contribui para uma sensação de bem-estar e equilíbrio no trajeto dos pedestres ( $\mathrm{LYNCH}$, 2011), sendo essencial para o conforto no deslocamento. Kohlsdorf (1996) afirma que elementos urbanos criam a identidade e a legibilidade do ambiente, proporcionando possibilidades para a localização e um deslocamento consciente às pessoas. Esses elementos podem ser efetuados pelas fachadas ativas, que, a partir da identidade criada pelos estabelecimentos presentes nos andares térreos, geram a percepção de orientação no espaço. 
Karssenberg et al (2015) apontam para a importância da flexibilidade de níveis de aluguel para evitar a gentrificação. Os mesmos autores afirmam ainda que, quando necessário, deve-se investir na regeneração do bairro e no controle sobre os imóveis, a partir da diversidade em áreas urbanas, concentrando e preservando as lojas especializadas, serviços e restaurantes. Para que esses comércios de pequena escala possam perpetuar, é importante que exista: (i) baixo aluguel ou propriedade particular; (ii) pequena escala das salas nos andares térreos; e, (iii) diversidade. Outra importante medida que deve ser tomada, para evitar a gentrificação, é a colaboração com os órgãos públicos para que os usos dos andares térreos sejam preservados, pois, caso contrário, eles podem ser ocupados, também, como habitação.

Karssenberg et al (2015) e Gehl (2013) apresentam algumas diretrizes que podem ser usadas para o desenvolvimento de projetos urbanos, são elas: (i) dar continuidade ao alinhamento das fachadas; (ii) incentivar usos no andar térreo que funcionem como espaços de encontros, como lojas, bares e restaurantes; estabelecer um mínimo de 10 acessos a cada 100 metros de fachada, a fim de criar diversidade e atrativos para o pedestre; (iii) estipular um mínimo de 4 metros de pé-direito no andar térreo, tornando possível a implementação de espaços públicos e culturais; e, (iv) determinar premissas de desenho para fachadas e garantir que 0 
aluguel do andar térreo tenha um valor acessível a diversos tipos de público, para que se formem pequenas unidades com maior número de acessos e variação de funções.

Karssenberg et al (2015) e Gehl (2013) ressaltam, ainda, a importância de quatro fatores para o bom desenvolvimento das fachadas ativas, são eles: (i) escala humana, com edificações em pequena escala e vias motorizadas com fluxo controlado; (ii) autenticidade, atribuindo também a característica de diversidade nos serviços instalados nos estabelecimentos; (iii) fachadas dinâmicas, possibilitando a utilização de diversos tipos de segmentos; e (iv) permeabilidade, podendo ser ela física ou visual.

No âmbito social do cenário brasileiro, observa-se uma carência da aplicação das fachadas ativas nas habitações de interesse social produzidas no programa Minha Casa Minha Vida (CAIXA ECONÔMICA FEDERAL, 2009), para a faixa de até três salários mínimos. Esses empreendimentos apresentam aspectos semelhantes: (i) distância do centro das cidades; (ii) limites demarcados por muros; e, (iii) predominância do uso residencial. Santos e Jorge (2014) destacam que esse cenário prejudica o espaço urbano, impactando na qualidade de vida dos moradores.

Verifica-se, além disso, uma intensa padronização dos projetos desses conjuntos habitacionais, de forma que os 
aspectos ambientais e culturais do entorno não sejam considerados. As técnicas construtivas, dimensões espaciais, disposição dos ambientes e o conforto ambiental não satisfazem às diversidades urbanas, bioclimáticas, sociais, culturais e tecnológicas dos municípios, sendo que o descuido com os aspectos do arredor pode ser confirmado pela semelhança entre os projetos, mesmo quando implantados em regiões diferentes.

Paz (2014) ressalta a questão da centralização presente nos empreendimentos, não favorecendo o convívio, a participação e a sociabilidade. Observa, ainda, que os projetos, realizados na forma de condomínio fechado, são definidores dessa característica ao reforçarem os aspectos de espaço fechado, privado, murado e não aberto ao público, contribuindo com a criminalidade.

Hertzberger (1999) destaca a importância da "rua de convivência", que consiste na ideia de que as pessoas devem se apropriar das vias lindeiras as suas moradias de modo a estimular a integração da vizinhança, aproximando membros da mesma comunidade. Para que isso aconteça, deve-se pensar na implantação das unidades residenciais em relação ao lote, dispondo as aberturas voltadas para a rua. Com a atribuição da rua como espaço comunitário, é despertado o sentimento de segurança por parte dos moradores, à medida que a movimentação na rua é incentivada. 
Diante do exposto, percebe-se a falta dos conceitos norteadores das fachadas ativas nos conjuntos habitacionais populares nacionais, estabelecendo espaços urbanos sem identidade, sem uma formação comunitária e sem o estabelecimento de laços de vizinhança, o que evidencia a segregação social. Conforme afirma Hertzberger (1999), os projetos urbanos bem estruturados facilitam encontros entre as pessoas de modo a atrair o usuário para o espaço público, fazendo com que ele crie uma relação de pertencimento. Portanto, o habitar deve permitir, amplamente, o processo de integração dos moradores, oportunizando encontros entre os vizinhos e promovendo, assim, a segurança, a habitabilidade e a convivência entre as pessoas.

\section{Estudo de caso: fachadas ativas no bairro Moinhos de Vento}

O bairro Moinhos de Vento (figura 3) se localiza em Porto Alegre, capital do Rio Grande do Sul que está situada às margens do lago Guaíba. Nas proximidades da zona central da cidade, situa-se o bairro que consistiu no objeto de estudo da pesquisa, sendo o perímetro escolhido delimitado pelo eixo da Rua Padre Chagas e o primeiro quarteirão da Rua Félix da Cunha. O trecho inicia na Rua Fernando Gomes e termina na Rua Olavo Barreto Viana, no encontro com o Shopping Moinhos de Vento, sendo acrescido pela quadra que conecta até a Rua Tobias da Silva (figura 3). 


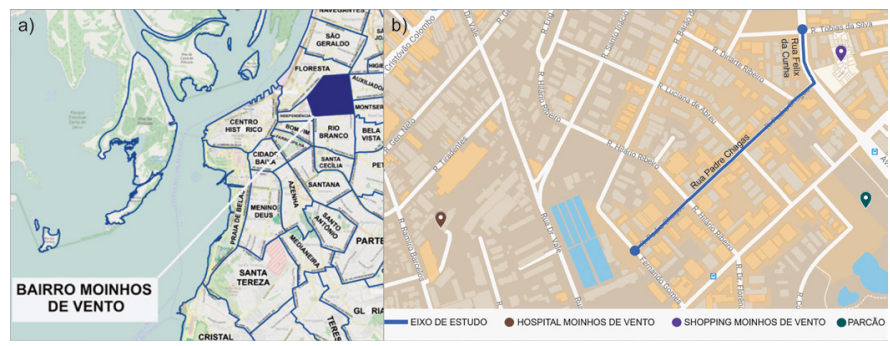

Figura 3 | a) Localização do bairro Moinhos de Vento. Fonte: PPDUA de Porto Alegre (2016); (b) Localização do eixo de estudo. Fonte: Adaptado de Google Maps (2018).

O bairro Moinhos de Vento é caracterizado, principalmente, pela existência de residências preservadas. As edificações datam do início do século XX e a região abriga um importante parque (Parcão) e um hospital (Hospital Moinhos de Vento), que também acompanham o histórico da região desde o início do seu desenvolvimento, agregando valores de orientabilidade e identidade para a população. Esses equipamentos atraem movimentação para o bairro, trazendo pessoas de várias regiões de Porto Alegre.

O espaço, frequentado por moradores, visitantes e trabaIhadores ${ }^{3}$, comporta variados tipos de atividades em seus andares térreos, sendo eles diferenciados entre si e com um caráter particular. Podem ser encontrados diversos es-

3. Foi realizado um questionário, no percurso da Rua Padre Chagas até a Rua Felix da Cunha, no dia 08 de julho de 2017, com doze pessoas, sendo seis mulheres e seis homens. Dentre essas pessoas, duas trabalhavam na região, quatro estavam a passeio e seis relataram ser moradores do bairro. 
tilos de bares, cafés, bistrôs e restaurantes; também comporta armazéns e mercados, que são especializados em produtos incomuns, importados e de difícil acesso. Além disso, existem lojas, boutiques, feiras e artigos artesanais com mercadorias diferenciadas (figura 4). Os pavimentos superiores são, na maioria das vezes, sobreloja ou moradia, as quais se limitam de três a quatro pavimentos.
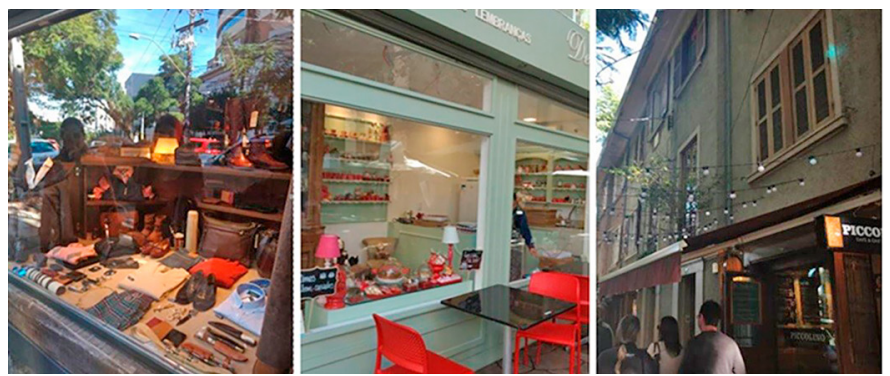

Figura 4 | Estabelecimentos localizados na Rua Padre Chagas.

Fonte: Autores (2018).

As residências preservadas foram readaptadas aos usos. Onde antes existiam garagens, abriu-se o espaço para a rua e criaram-se estabelecimentos que se relacionam com as calçadas por bancos, mesas e cadeiras, tratamento paisagístico, tratamento das calçadas e transparência nas fachadas. As mesas e cadeiras receberam tratamento com toalhas ou pinturas (figura 5), assim como a vegetação, que é trabalhada em vasos ou algum tipo de estrutura que chame a atenção sem destoar do conjunto. Há aquecedores 
no inverno e a largura das calçadas varia entre três e cinco metros. Nos casos em que acontecem recuos frontais diferenciados, a leitura do espaço se torna fragmentada.

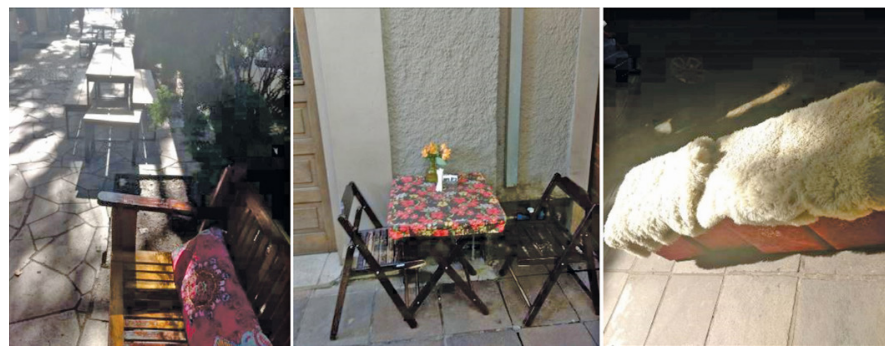

Figura 5 | Estabelecimentos localizados na Rua Padre Chagas. Fonte: Autores (2018)

As residências preservadas foram readaptadas aos usos. Onde antes existiam garagens, abriu-se o espaço para a rua e criaram-se estabelecimentos que se relacionam com as calçadas por bancos, mesas e cadeiras, tratamento paisagístico, tratamento das calçadas e transparência nas fachadas. As mesas e cadeiras receberam tratamento com toalhas ou pinturas (figura 5), assim como a vegetação, que é trabalhada em vasos ou algum tipo de estrutura que chame a atenção sem destoar do conjunto. Há aquecedores no inverno e a largura das calçadas varia entre três e cinco metros. Nos casos em que acontecem recuos frontais diferenciados, a leitura do espaço se torna fragmentada.

Outro diferencial do bairro são os acontecimentos esporá- 
dicos, como pequenos shows em bares e feiras (figura 6) organizadas, na maioria das vezes, nos finais de semana. Esses eventos reforçam o convívio entre pessoas e agregam personalidade ao ambiente. A arborização também é um aspecto presente no local; além da estética, a vegetação de grande porte contribui com o conforto ambiental do local. As vias possuem vagas de estacionamento adjacentes ao meio fio, de modo a fazer a transição entre o movimento de veículos das vias e o movimento de pedestres nas calçadas, contribuindo com a segurança.
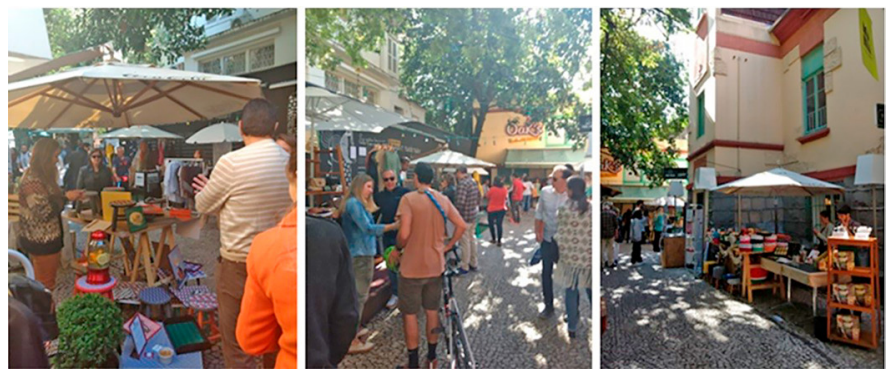

Figura 6 | Evento Maria Cultura realizado no Pátio Rizzo.

Fonte: Autores (2018).

Todos os aspectos mencionados existentes no bairro Moinhos de Vento fazem com que as fachadas ativas se tornem um atrativo para as pessoas, movimentando e diversificando o entorno, já que a zona de proteção garante que o movimento de pedestres possua uma barreira visual 
e física em relação ao movimento de veículos. No trecho analisado, não foi constatada a ocorrência de gentrificação, pois a maioria das lojas e restaurantes é de pequena escala, especializada, e seus estilos fazem parte da origem do bairro. Em vista disso, a ambiência do espaço é satisfatória, transformando o bairro Moinhos de Vento em ponto de referência na memória coletiva.

\section{Diretrizes projetuais para implantação de fachadas ativas}

As fachadas ativas são estabelecidas não apenas pelas atividades desempenhadas no pavimento térreo como também pela maneira pela qual o espaço híbrido é tratado. As diretrizes projetuais que serão apresentadas têm por base os estudos de Gehl (2013), Karssberg et al (2015) e Hertzberger (1999), sendo tais conceitos amparados pelo estudo de caso realizado no bairro Moinhos de Vento e pelos estudos de Kronenberger (2017).

As principais características a serem alcançadas pelas fachadas ativas são: diversidade de usos; permeabilidade física e visual das fachadas; boa acessibilidade; tratamentos nos pisos dos passeios públicos; mobiliário urbano; fachadas e iluminação; densidade e largura das edificações; e, diversidade dos níveis de aluguel.

Kronenberger (2017), baseada nos estudos de Gehl (2013) e 
do TOD4 4 (2013), estabelece que o percentual de segmento de fachada visualmente ativo é de $90 \%$, sendo que abaixo de $50 \%$ é considerado insuficiente. Esse percentual corresponde ao segmento de calçada que possui conexão visual com o interior da edificação. Na pesquisa apresentada, foi possível verificar que as fachadas ativas têm uma relação direta com a cultura presente no espaço, e acredita-se que essa permeabilidade deve ser condizente com o clima, materiais utilizados no entorno e com a atividade da edificação. Os materiais empregados na estrutura e nos revestimentos das fachadas térreas devem condizer com os costumes e com o clima da região. Portanto, a porcentagem de permeabilidade visual pode variar de acordo com o clima, cultura e materiais de cada local.

Quanto à quantidade de acessos por percurso, Gehl (2013) defende que se deve garantir, no mínimo, 10 entradas a cada 100 metros, enquanto TOD (2013) estabelece que o mínimo seria de 5 acessos a cada 100 metros, sendo que menos do que 3 seria considerado insatisfatório. Contudo, acessos de garagens, saídas de emergência e acessos a depósitos não são considerados como elemento de acesso físico.

4. Consiste numa ferramenta de avaliação, focada na integração do transporte sustentável ao planejamento e uso do solo, que possibilita quantificar o planejamento e a eficiência de projetos. 
A densidade também é um atributo importante para o sucesso das fachadas ativas. No entanto, essa densidade deve acontecer em aproveitamento do solo e não em verticalidade, para que não se perca a escala humana. É interessante que edificações tenham de quatro a cinco pavimentos (GEHL, 2013), de forma que aproveitem a infraestrutura urbana existente, atraiam o maior número de pessoas e não ultrapassem em verticalidade. Em vias largas, considera-se que a altura das edificações não deva ultrapassar o dobro da largura da rua (KARSSNBER et al, 2015).

A diversidade das atividades ao articular residências, comércios e serviços aumenta a quantidade de pessoas, tornando o espaço mais movimentado e, consequentemente, mais seguro. Essa variação das atividades nos pavimentos térreos favorece a segurança dos espaços na medida em que mais pessoas nas ruas contribuem com a vigilância coletiva (JACOBS, 2003). É necessário que esses usos envolvam todos os períodos do dia, pois ambientes devem ser convidativos tanto durante o dia quanto no decorrer da noite. Portanto, prever ambientes que estimulem a copresença e a permanência das pessoas é uma forma de qualificar o espaço e promover a sua segurança.

Esses ambientes também devem ter o caráter da identidade local; os serviços prestados nos estabelecimentos do pavimento térreo devem ter relação com as características 
do bairro. Os pequenos empreendimentos representam a personalidade e a identidade do local, além de contribuir para os aspectos de orientabilidade e escala humana. Assim sendo, é necessário que se considere as particularidades culturais de cada lugar, com o intuito de que as pessoas se identifiquem com o lugar.

Mobiliário urbano, paisagismo e iluminação, implantados de maneira eficiente, facilitam a apropriação das fachadas ativas também durante os diversos períodos do dia. Quando instalados na escala das pessoas que circulam pelas calçadas, esses elementos criam as condições para se transitar com mais conforto e segurança. É necessário também que esses equipamentos sejam personalizados o bastante, de modo a tornar o ambiente mais atrativo.

A implantação de fachadas ativas está, na maioria das vezes, relacionada com o uso comercial no térreo da edificação. No entanto, deve-se observar zonas com caráter predominantemente residencial. É importante não permitir que se originem planos fechados nos limites do lote com a calçada, de forma a impedir a relação das edificações com o espaço aberto público. Kronenberger (2017) ressalta que a previsão de varandas, portas e janelas, projetadas estrategicamente, possibilita a integração dos moradores com vizinhos e pedestres, contribuindo com a vitalidade e segurança urbana. 
As diretrizes necessárias para se planejar fachadas ativas foram estabelecidas por meio dos conceitos abordados anteriormente. Essas diretrizes podem ser utilizadas pelo projetista urbano e também pelo profissional responsável por projetos de edificações. A inserção de fachadas ativas nas cidades traz benefícios não só aos pedestres como também aos comerciantes e proprietários de imóveis, visto que a maior movimentação de pessoas qualifica a economia e ainda valoriza o imóvel.

A diversidade de atividades (residencial, comercial e serviços) permite que um maior número de pessoas transite pelo ambiente e também reforça a identidade da região, estimulando a economia local (figura 7).

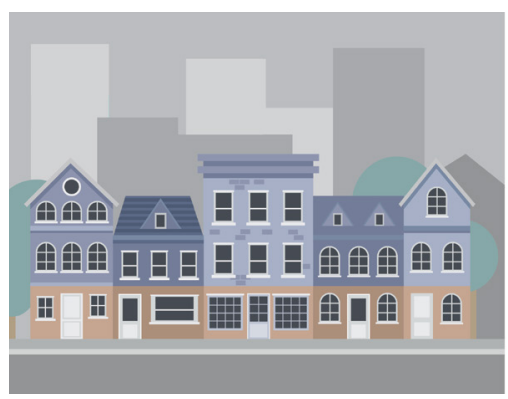

COMÉRCIO E SERVIÇOS

Figura 7 | Diversidade de usos.

Fonte: Autores (2018). 
É importante que as fachadas ativas sejam implantadas em zonas com densidade média ou alta, de modo a promover a movimentação das pessoas, impulsionando o êxito dos estabelecimentos comerciais (figura 8). Essa característica oferece uma maior sustentabilidade ambiental com o objetivo de aproveitar a infraestrutura urbana existente sem a necessidade de a levar a maiores distâncias ou a regiões pouco habitadas.

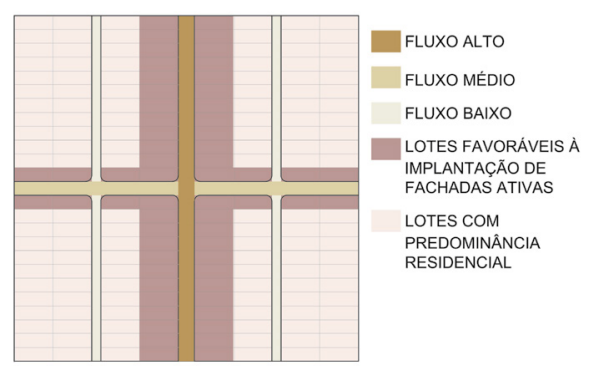

Figura 8 | Centralidade de regiões em vias movimentadas. Fonte: Autores (2018).

Os acessos são fundamentais para a ocorrência das fachadas ativas; sugere-se que sejam implantados, no mínimo, doze acessos a cada 150 metros. Salienta-se que esses acessos representam o número de lojas e entradas da edificação, sendo que entradas de veículos e de serviço não são consideradas elementos fisicamente acessíveis (figura 9). 


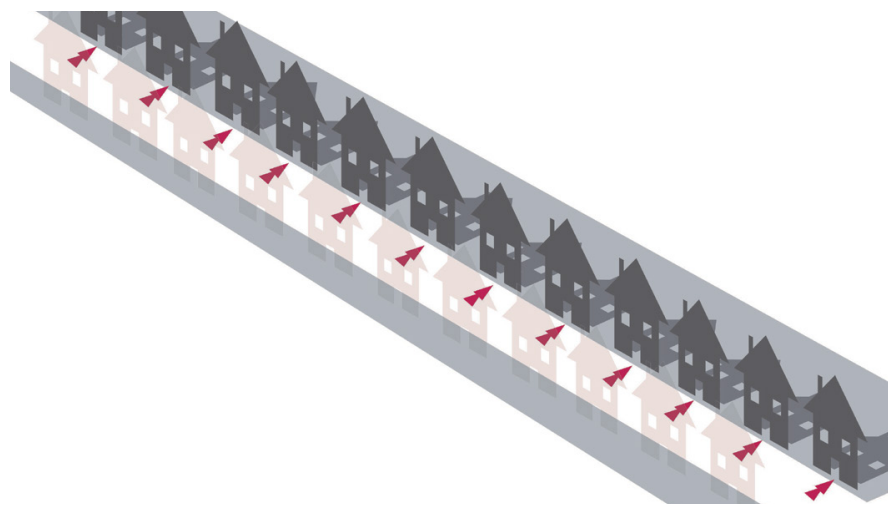

Figura 9 | Mínimo de 12 acessos a cada 150 metros.

Fonte: Autores (2018)

A permeabilidade nos térreos das edificações condiz com o segmento de calçada com conexão visual às atividades do interior da edificação (figura 10). Essa característica é relevante por reforçar a segurança decorrente da vigilância natural efetuada pelas pessoas que se encontram no interior das edificações e também por aquelas que se movimentam pela calçada.

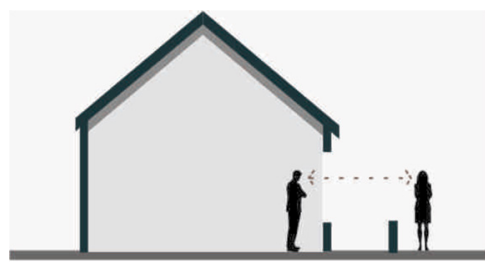

Figura 10 | Permeabilidade na fachada do pavimento térreo superior a $50 \%$. Fonte: Autores (2018). 
A partir do quinto pavimento, a conexão entre os pedestres e o edifício se perde devido aos sentidos de visão e de audição, que são ineficazes nessa distância vertical (figura 11). O controle nas alturas das edificações promove o domínio da escala humana, contribuindo com a boa ambiência dos espaços públicos abertos.

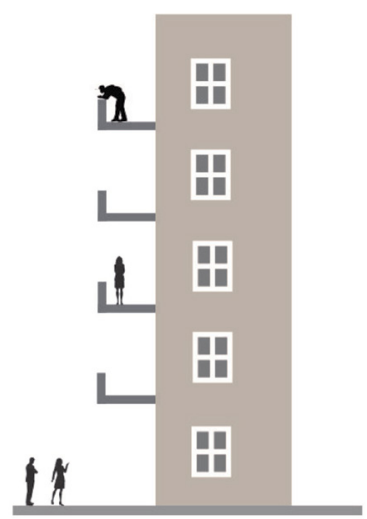

Figura 11 | Limite de cinco andares por edificação. Fonte: Autores (2018).

Recuos diferenciados nas fachadas resultam em fragmentação perceptiva do todo, fazendo com que o pedestre se sinta inseguro em percorrer o trajeto (figura 12). A continuidade nos limites frontais das edificações favorece a formação de uma unidade do conjunto espacial da quadra, permitindo o desenvolvimento da identidade do lugar. 


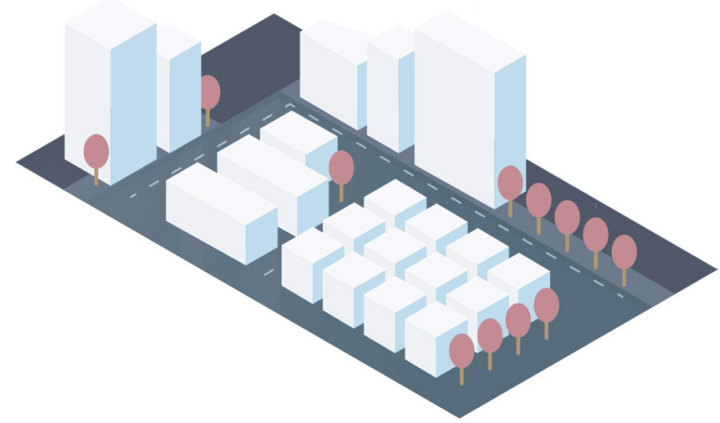

Figura 12 | Regularidade no alinhamento. Fonte: Autores (2018).

Incorporar, nos estabelecimentos, as peculiaridades do entorno possibilita a formação de uma identidade para o local e atrai diferenciados tipos de público (figura 13). Esse aspecto conecta as pessoas, reforçando a função social da cidade como local de encontro (GEHL, 2013).

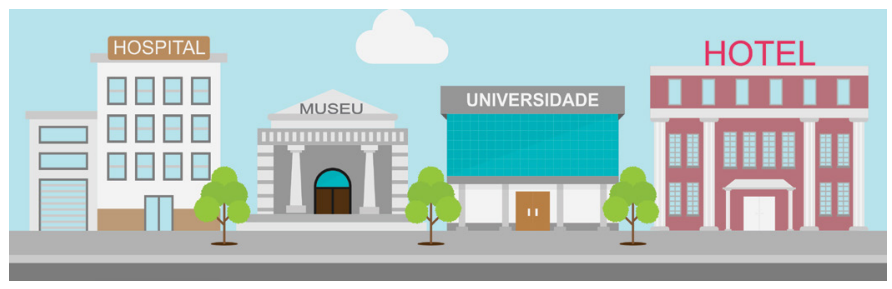

Figura 13 | Estabelecimentos com características relacionadas à cultura do local. Fonte: Autores (2018). 
Boas acessibilidade e mobilidade nas vias incentivam a movimentação urbana, visto que isso é fundamental para que aconteça uma proteção do movimento de pedestres nas calçadas com o trânsito motorizado. Essa proteção pode ser formada por estacionamento, ciclovia, vegetação ou outros elementos urbanos que façam o barramento visual e físico da zona com movimento acentuado de veículos (figura 14). Destaca-se, ainda, que as calçadas e térreos devem priorizar a mobilidade das pessoas, mantendo a boa ambiência do espaço.

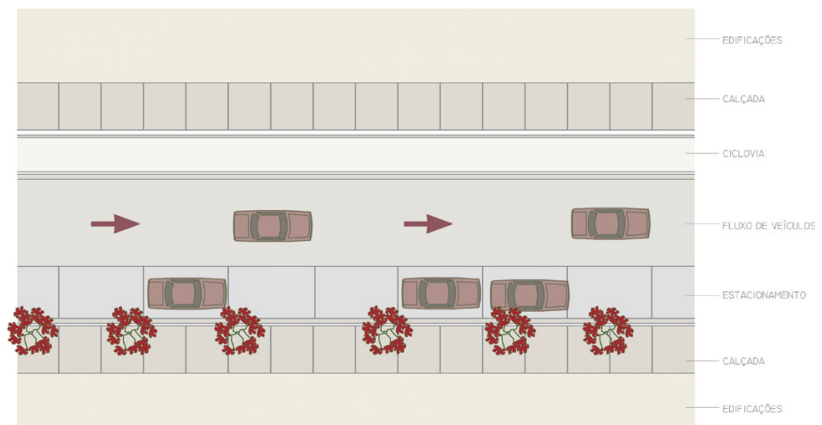

Figura 14 | Existência de uma zona de proteção entre a faixa motorizada e a de pedestres. Fonte: Autores (2018)

Sugerem-se quadras com não mais do que 150 metros de comprimento, de modo a preservar a percepção visual de uma esquina a outra (figura 15). Deve-se, ainda, priorizar a escala humana no mobiliário urbano, paisagismo, iluminação e calçamento. 


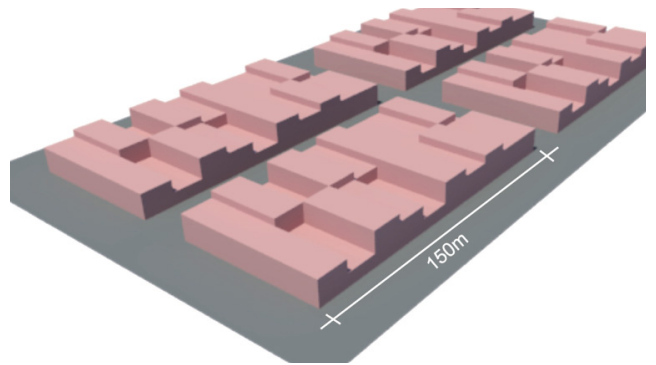

Figura 15 | Quadras com limite de 150 metros de extensão. Fonte: Autores (2018).

Os espaços nos andares térreos devem permitir a adaptação de diferentes tipos de usos (figura 16). A possibilidade na transformação dos espaços viabiliza que diferentes tipos de usos se estabeleçam nesses ambientes e facilita a comercialização imobiliária das salas térreas.

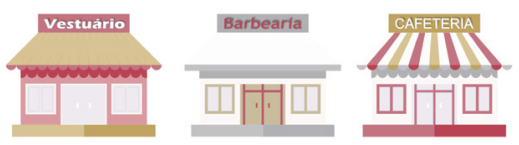

Figura 16 | Fachadas dos térreos estruturadas de forma a possibilitar a transformação dos espaços. Fonte: Autores (2018).

Deve-se garantir diversos níveis de aluguel nas lojas térreas, buscando evitar a gentrificação. Ainda sobre esse aspecto, deve-se trabalhar juntamente ao órgão público para preservar os usos de comércio e serviços, evitando, assim, que esses ambientes venham a se tornar unidades habitacionais. 
Em síntese, fachadas ativas correspondem aos pavimentos térreos das edificações localizados nos limites frontais do alinhamento, com aberturas voltadas para o espaço aberto público. Representam a relação entre as edificações e a calçada, contribuindo para a segurança e qualidade do espaço urbano, pois ruas atrativas são mais ocupadas pelas pessoas. Cabe destacar que a conexão decorre de diversos fatores de espacialidade associados ao modo de conexão dos limites, que, se existentes no pavimento térreo, podem configurá-lo em ativo e, por conseguinte, interligado ao espaço urbano. Tal espaço deve estar relacionado a um sentido de identificação para com a cultura do local, refletindo um senso de ocupação que pode ser apropriado pela população. Esse senso de ocupação, por sua vez, relaciona-se à orientação e à identificação do pedestre no espaço.

\section{Considerações finais}

A partir das análises dos conceitos aplicados no estudo de caso, no bairro Moinhos de Vento, foi possível estabelecer variáveis que tornam esses ambientes atrativos. Verificou-se, também, que a realidade brasileira, principalmente no campo da habitação social, carece de muitos dos benefícios que as fachadas ativas podem proporcionar para a comunidade, gerando insegurança na maioria dos empreendimentos implantados no Brasil na última década. 
As variáveis originaram diretrizes projetuais, consistindo em: (i) diversidade de usos; (ii) centralidade; (iii) permeabilididade; (iv) acessibilidade; (v) escala humana; (vi) identidade; (vii) movimento de pedestres e veículos; (viii) implantação dos edifícios; (ix) limite na extensão das quadras; $(x)$ espaços térreos adaptáveis; e, (xi) flexibilização do aluguel. Essas diretrizes visam auxiliar o projetista no momento de produção dos desenhos desses ambientes e na requalificação de espaços urbanos. Portanto, a pesquisa se mostrou capaz de explanar a respeito da importância das fachadas ativas no desenho urbano e de determinar as diretrizes para implantação dessas. Ainda assim, acredita-se que existe um campo maior para pesquisas futuras que incorporem cada vez mais contribuições de estudos junto à realidade brasileira no que concerne à influência das fachadas ativas na qualidade da ambiência urbana.

\section{Referências}

AMSTERDAM. Gezondheid En Welzijn Voor de Amsterdammer in 2025. Reframing Studio, 2016.

BARROSO, Celina de Pinho. Conforto e orientação na percepção da acessibilidade urbana: área central de Pelotas/ RS. UFRGS. Dissertação (Mestrado). Porto Alegre, 2012.

BASSINI, André Reis. Espaços de transição: entre a arquitetura e a cidade. FAU-UPM. Dissertação (Mestrado). São Paulo, 2014

BELO HORIZONTE. Os instrumentos de política urbana previstos no Projeto de Lei do Plano Diretor. Secretaria Municipal de Política Urbana. Belo Horizonte, 2017. 
CAIXA ECONOMICA FEDERAL. Cartilha: Minha Casa Minha Vida.

Brasília, 2009.

CULLEN, Gordon. A paisagem urbana. Tradução de Isabel Correia e de Carlos de Macedo a partir da edição de 1983. Lisboa: Edições 70, 2015.

CURITIBA. Lei Municipal no 14771 de 2015. Revisão do Plano Diretor de Curitiba. Diário Oficial do Município: Curitiba, 17, dez. 2015.

GEHL, Jan. Cidades para pessoas. São Paulo. Perspectiva, 2013.

GOOGLE MAPS. Mapa do bairro Moinhos de Vento. 2017. Disponível em: https://www.google.com.br/maps. Acesso em: 21 dez. 2017.

HERTZBERGER, Herman. Lições de arquitetura. São Paulo: Martins Fontes, 1999.

ITDP BRASIL. Padrão de qualidade ao desenvolvimento orientado ao transporte sustentável (TOD). 2013.

JACOBS, Jane. Morte e vida de grandes cidades. Tradução Carlos S. Mendes Rosa. São Paulo: Martins Fontes, 2003.

KARSSENBERG, Hans; LAVEN, Jeroen; GLASER, Meredith e VAN'T HOFF, Mattijs. A cidade ao nível dos olhos: lições para os plinths. Porto Alegre: EDIPUCRS, 2015.

KOHLSDORF, Maria Elaine. A apreensão da forma da cidade. Brasília: EdUnB, 1996.

KRONENBERGER, Bruna da Cunha. Fachadas ativas. Estudo técnico. Governo do Distrito Federal, 2017.

LYNCH, Kevin. A imagem da cidade. Tadução: Jeferson Luiz Camargo. $3^{\text {a }}$ ed. São Paulo: WMF Martins Fontes, 2011.

MELBOURNE. CH2: Setting a new world standard in green building design. City of Melbourne, 2018.

NYC PLANNING. Projeto ativo: moldando a experiência na calçada. Departamento de Planejamento Urbano da Cidade de Nova York. 2013. Disponível em: < https://www1.nyc.gov/site/planning/plans/ active-design-sidewalk/active-design-sidewalk.page >. Acesso em: 10 jan. 2017.

PACHECO, Priscila. Paisagens urbanas e a (in)felicidade dos pedes- 
tres. Thecityfixbrasil. 2016

PAZ, Rosangela Dias de Oliveira. Avaliação do trabalho social e dos impactos na vida das famílias no programa Minha Casa Minha Vida, no município de Osasco/SP. Artigo desenvolvido no Programa de Estudos Pós-Graduados em Serviço Social. PUC-SP, 2014.

PORTO ALEGRE. Plano Diretor de Desenvolvimento Urbano Ambiental. Porto Alegre.2016. Disponível em: < http://www2.portoalegre.rs.gov.br/spm/default.php?p_secao=310>. Acesso em: 20 dez. 2017.

SANTOS, Cynthia Marconsini Loureiro; JORGE, Liziane de Oliveira. Método de avaliação da qualidade da inserção urbana aplicado a um empreendimento residencial do programa Minha Casa Minha Vida. Revista Arq.Urb.USJT, 2014.

SÃO PAULO. Lei n 16.050 de 2014: Plano Diretor Estratégico do Município de São Paulo. Diário Oficial do Município: São Paulo, 31 jul. 2014.

STOCKHOLMS. Översiktsplan för Stockholms stad. Stockholms stad, 2018.

243

VIVAN, Mariana; SABOYA, Renato. Arquitetura, espaço urbano e criminalidade: relações entre espaço construído e segurança, com foco na visibilidade. II Encontro Nacional da Anparq. Natal, 2012.

Recebido em: 18/05/2018

Aprovado em: 02/07/2018 